\title{
EDITORIAL
}

$$
\text { ๙ }
$$

\section{INVESTIGAÇÃO CRIMINAL E NOVAS TECNOLOGIAS PARA OBTENÇÃo DE PROVA}

Os meios de obtenção de prova utilizados na fase preliminar da persecução penal, notadamente nos casos de criminalidade organizada, sofisticaram-se. Há certo tempo as legislações têm previsto meios excepcionais de obtenção de prova ou métodos ocultos de investigação, carregados, como o próprio nome diz, de sigilo. É o caso, entre nós, das possibilidades previstas na Lei n. 12.850/2013.

As características deste tipo de criminalidade, que é contínua ou permanente e não tem vítima direta, dentre outras especificidades, representam desafios ao modelo tradicional de investigação preliminar, que se viu impelido a lançar mão de novos instrumentos de persecução penal, como interceptações telefônicas, telemática, captação ambiental de sinais eletromagnéticos, ópticos ou acústicos, e métodos como ação controlada e infiltração de agentes, dentre outros.

Neste sentido, as possibilidades de uso da tecnologia, por meio da busca de rastros, dados e informações, armazenados ou em trânsito, têm alterado significativamente as formas tradicionais de investigação criminal. Ademais, as tecnologias de vigilância, especialmente em meio digital, têm tornado opaco o limite de separação entre prevenção e repressão dos delitos, entre segurança pública e persecução penal.

Por outro lado, a proteção de sigilo das comunicações e privacidade, as questóes do uso de dados pessoais no âmbito da segurança pública e em investigações criminais, tensionam tais usos.

Tais assuntos vêm exigindo reflexão e esforços a fim de discutir problemas prementes, tensionar possibilidades, desenhar limites, verificar a suficiência da regulação normativa, a excepcionalidade ou expansão do uso destas tecnologias na investigação criminal. 
Com estas perspectivas, os autores que escreveram para o dossiê "Investigação criminal e novas tecnologias para obtenção de prova", que ora vem a público, abordam questões essenciais no âmbito do uso dos chamados meios excepcionais ou ocultos de investigação criminal, identificando problemas atuais de alguns meios de obtenção de prova intrusivos da esfera privada.

O debate sobre o acesso a dados encriptados por autoridades, no contexto de investigações criminais, se intensificou nos últimos casos. A implementação massiva de criptografia forte em serviços e produtos tem desafiado as técnicas tradicionais de investigação. $\mathrm{O}$ embate entre a possibilidade de imposição de mecanismos de acesso excepcional de criptografia, para acesso a dados armazenados e em comunicação, e a questão de segurança e privacidade dos usuários em geral, sobre qual direito - ambos públicos - deve ser sacrificado em prol do outro, ocupa hoje o cenário do direito.

Nesta discussão, está o texto de Caio Porto Ferreira Correio, sobre "Hacking e infiltração policiais em resposta ao uso de criptogafia por organizaçôes criminosas", que analisa o uso de medidas de investigação em resposta ao uso de criptografia por organizações criminosas. $\mathrm{O}$ artigo trata dos esforços dos órgãos responsáveis pela investigação criminal para desenvolver e aplicar novas tecnologias para obtenção de prova, bem como atividade de inteligência.

Em outro sentido, o artigo de Gianluca Martins Smanio, intitulado "A busca reversa por dados localização na jurisprudência do Superior Tribunal de Justiça: análise crítica do RMS 61.302/RJ", trata da questão da obtenção de dados de localização e mecanismo de busca reversa de tais dados, não disciplinada em lei. Reconhece que o desenvolvimento das tecnologias da informação permitiu a utilização de dados pessoais para investigar a ocorrência do delito e a identificação da autoria, mas defende que a busca por tais dados, com é o de caso da informação quanto à localização, envolve restrição a direitos fundamentais do investigado, como a privacidade e o sigilo da comunicação dos dados, que são tutelados pela Constituição da República, daí porque seria necessária regulamentação mais precisa para permitir tal meio de obtenção de prova, em contraposição à legislação esparsa e omissa hoje existente. A partir deste ponto de vista, promove análise crítica 
de precedente do Superior Tribunal de Justiça, acerca da construção jurisprudencial permissiva da busca reversa por dados de localização.

O texto escrito por Igor Isídio Gomes da Silva, sobre "Acesso a dados telefônicos em investigaçôes de repressão ao crime organizado: de cheque em branco a anteparo garantidor", aborda a questão da autorização judicial inespecífica quanto a dados telefônicos, quando expedida no procedimento em que deferida interceptação telefônica. Dada a resistência ao seu uso, propõe elementos que devem ser averiguados para verificação da legitimidade da autorização judicial, como proporcionalidade da medida, delimitação quanto à utilização e controle judicial de implementação pelo órgão investigativo.

O presente dossiê caminha assim por artigos que analisam as questões mais sensíveis ao tema do uso de novas tecnologias no processo penal: novas questóes apresentadas, insuficiência normativa, urgência prática para o desenvolvimento da atividade de investigação. Os textos dialogam, mostram a mesma inquietação e contribuem efetivamente para o debate sobre o tema e para a pesquisa.

Mas este número da Revista não para por aqui. A publicação traz também textos diversos, sobre problemas outros que assolam a atividade de polícia, ora de investigação, ora de prevenção da prática de delitos.

Sobre a atividade de prevenção, o artigo de Wellington Clay Porcino, "Politicas Territoriais de Segurança no Brasile na França: uma comparação entre as Unidades de Polícia Pacificadora (UPP) e o Policiamento de Segurança do Cotidiano (PSQ)", produto parcial de estágio de doutorado realizado na Universidade de Paris III (Sorbonne-Nouvelle), mostra a questão da gestão de segurança pública, comparando a experiência brasileira das UPPs (Unidades de Polícia Pacificadoras, política implementada no Rio de Janeiro há cerca de dez anos) com o recente PSQ (Policiamento de Segurança do Cotidiano), na França. Muito embora experiências com intensidade e reflexos diversos, ambas são fundadas na ideia de exercício do poder estatal legítimo, no tocante à segurança pública, em áreas sensíveis.

O artigo de José Fernando Moraes Chuy, chamado "Novo terrorismo? O fracasso da guerra ao terror à radicalização virtual", trata da 
política criminal instituída depois do 11 de Setembro e as consequências secundárias advindas da priorização do uso da força militar no enfrentamento do politicamente rotulado novo terrorismo. Mostra que, ao adjetivar o terrorismo de "novo", corre-se o risco de abandonar o conhecimento pretérito. Apresenta a formação de segunda geração de líderes terroristas por meio da radicalização virtual como consequência da política belicosa adotada. Questiona esta política retribucionista e defende, em seu lugar, a adoção de estratégia preventiva e repressiva de forma democrática e transparente.

Nesta mesma linha, muito embora em outro contexto, o artigo "Da ética policial: um pressuposto no uso da força em Portugal", de Bruno Miguel Fena Torres, analisa os padrões éticos que devem ser adotados na intervenção policial, notadamente na questão do uso da força, de forma ter atividade legítima na promoção da segurança pública em um Estado Democrático de Direito.

Há também dois artigos sobre corrupção, com perspectivas de abordagem bastante distintas, mas igualmente importantes.

O artigo apresentado por Carlos Frederico Portella Santos Ribeiro, Joselito de Araujo Sousa e Nelson Levy Kneip de Freitas Macedo, intitulado "Polícia Federal: função vertebradora, combate à corrupção e os desvios de conduta policial", cuida da questão da punição promovida pela polícia, em casos identificados como de corrupção interna. A partir de comparação de dados de levantamento feito pela Controladoria Geral da União sobre punições de servidores públicos federais pela prática de corrupção e também de notícias publicadas na mídia, mostra que a Polícia Federal trata com mais rigidez do que outros órgãos do Poder Executivo Federal os casos de corrupção interna, tendo expulsado oito vezes mais servidores do que a média geral. Mostra também que a atuação da repressão interna em casos de corrupção é essencial para legitimar a atuação da Polícia Federal na sua atividade externa.

O outro artigo que versa sobre corrupção é um estudo de caso, a partir das eleições de 2018 no Estado do Acre. O artigo de Caio de Alcantara Moura Belo, "O uso de candidaturas 'laranjas' dentro do contexto do financiamento público de campanhas no estado do Acre: um estudo de caso", analisa uma nova dinâmica de corrupção eleitoral que 
ganhou curso depois da reforma política e da definição de cotas de gênero, com uso de candidaturas de fachada ("laranjas") implementadas dentro de estratégias partidárias, assim como desvios de recursos públicos que financiam campanha. Ressalta que embora o estudo se debruce sobre caso, revela elementos comuns que permitem eficiência na repressão e também indicativos de prevenção de tais ocorrências, a partir da identificação de um padrão de atuação, o que pode ser replicado.

O trabalho de Rodrigo dos Santos Andrade, "Greve no trabalho do policial militar", questiona a vedação constitucional do direito à greve por policial militar. Considera abusiva a proibição absoluta, defendendo que o direito deveria ser regulado, em respeito à liberdade de expressão e manifestação, permitindo desta forma aos policiais militares paralisarem suas atividades como forma de revelar os riscos da função, solicitando armamento adequado, viaturas, acompanhamento médico e psicológico e vencimentos condizentes com a atividade.

É inegável o valor da prova científica nas investigações criminais e, consequentemente, nas ações penais. O trabalho "Aplicação da teoria das filas, com prioridades, à área de perícia documenstocópica de uma Superintendência da Polícia Federal", de Roosevelt Alves Fernandes Leadebal Junior, traz trabalho empírico, de análise do comportamento do sistema de atendimento do setor de perícia documentoscópica em uma unidade de perícia da Polícia Federal, observando suas filas de atendimento de alta e baixa prioridades. Depois, mostra que é possível fazer uso dos resultados obtidos como ferramenta para superar eventuais gargalos no sistema.

Especificamente sobre atividade pericial, o trabalho intitulado "Os efeitos para uso policial da variação da massa e velocidade do projétil na energia cinética da munição e no recuo da arma de fogo", de Giovani Vilnei Rotta e José Antonio da Silveira Júnior, cuida de métodos de análise e avaliação, ilustrando a proposta com estudo de caso.

Os textos todos assentam tônica comum: o dilema entre eficiência e garantias fundamentais, propondo formas de exercício da atividade policial de maneira a validamente contribuir para um modelo próprio de nossos tempos, que não despreza as intrigantes ques- 
tões postas à atividade da polícia, os avanços tecnológicos e as novas possibilidades de atuação, mas sempre com orientação de legitimidade constitucional e legalidade estrita.

São Paulo, 15 de maio de 2021.

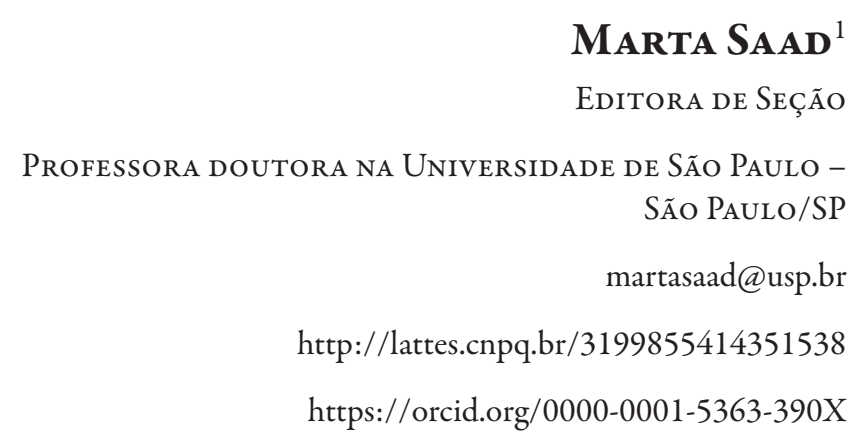

1 Professora Doutora do Departamento de Direito Processual da Faculdade de Direito da Universidade de São Paulo. Doutora e Mestre em Direito Processual Penal pela USP. Ex-Presidente do IBCCRIM (Instituto Brasileiro de Ciências Criminais). Presidente da REDE Ibero-Americana de Advocacia Criminal. Advogada. 